\title{
Impacts of the solar eclipse of 29 March 2006 on the surface ozone concentration, the solar ultraviolet radiation and the meteorological parameters at Athens, Greece
}

\author{
C. Tzanis ${ }^{1}$, C. Varotsos ${ }^{1}$, and L. Viras ${ }^{2}$ \\ ${ }^{1}$ University of Athens, Department of Applied Physics, Panepistimiopolis Build. Phys. 5, 15784, Athens, Greece \\ ${ }^{2}$ Ministry of Environment, Directorate of Air and Noise Pollution Control, 147, Patision Str., 11251 Athens, Greece \\ Received: 1 August 2007 - Published in Atmos. Chem. Phys. Discuss.: 9 October 2007 \\ Revised: 3 January 2008 - Accepted: 3 January 2008 - Published: 31 January 2008
}

\begin{abstract}
In this study the variations in the surface ozone concentration, the solar ultraviolet radiation and the meteorological parameters at the ground before, during and after the total solar eclipse of 29 March 2006 have been examined. This analysis is based on the measurements performed at four stations located in the greater Athens basin in Greece. The experimental data demonstrated that the solar eclipse phenomenon affects the surface ozone concentration as well as the temperature, the relative humidity and the wind speed near the ground. The decrease in the surface ozone concentration that observed after the beginning of the eclipse event lasted almost two hours, probably due to the decreased efficiency of the photochemical ozone formation. The reduction of the solar ultraviolet radiation at 312 and $365 \mathrm{~nm}$ reached $97 \%$ and $93 \%$ respectively, while the air temperature dropped, the relative humidity increased and the wind speed decreased.
\end{abstract}

\section{Introduction}

The solar eclipse being a rare natural phenomenon gives an opportunity to investigate how the photochemical processes react to the comparatively fast solar radiation changes.

The plausible variations in the stratospheric composition caused by natural processes like a solar eclipse have been among the most attractive issues for many workers (Bojkov, 1968; Wuebbles and Chang, 1979; Elansky et al., 1983; Burnett and Burnett, 1985; Mims and Mims, 1993; Zerefos et al., 2000, Gogosheva et al., 2002; Tzanis, 2005; Varotsos, $2002,2004,2005 a)$. In particular, the variation in total ozone (TOZ) content during a solar eclipse event has been attributed mainly to the cooling of the atmosphere and, therefore, the

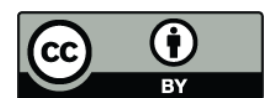

Correspondence to: C. Varotsos (covar@phys.uoa.gr) generation of internal gravity waves (Chimonas and Hines 1970; Chimonas and Hines, 1971; Zerefos et al., 2007; Reid et al., 1994) as well as the alteration of the photochemical balance.

However, the number of studies exploring the effects of solar eclipse on surface temperature and surface winds as well as on surface ozone (SOZ) and its precursors is relatively small (Srivastava et al., 1982; Fernadez et al., 1993; Zerefos et al., 2001; Kolev et al., 2005; Tzanis, 2005, Gerasopoulos et al., 2007).

The experimental data obtained from different observational sites in Bulgaria during the solar eclipse of 11 August 1999, demonstrated that the influence of the phenomenon was manifested with a certain delay and the duration of the impact of the eclipse on the ground ozone concentration was almost two hours (Kolev et al., 2005).

A decrease of around 10-15 ppbv in SOZ concentration has been observed at Thessaloniki, Greece, during the solar eclipse of 11 August 1999 (Zerefos et al., 2001), while the percentage change of SOZ concentration at Athens, Greece was maximized one hour after the solar eclipse maximum and the greater values of SOZ percentage change were observed at the Patision station, an urban station located in the central part of the Athens basin (Tzanis, 2005). The ozone profile measurements over Thessaloniki during the solar eclipse of 11 August 1999 indicated also an ozone decrease up to $2 \mathrm{~km}$ with a lag-time between the maximum of the eclipse and the maximum of the induced ozone decrease (Zerefos et al., 2001).

The effect of various meteorological parameters on the variability of the surface ozone and its precursors in the Greater Athens area (a site in the Mediterranean region, where very frequent photochemical pollution episodes occur), have been discussed in a number of recent publications (Kondratyev and Varotsos, 1995; Varotsos and Kondratyev, 1995; Ziomas et al., 1998; Varotsos et al., 2001; Varotsos et al., 2003, 2005; Varotsos and Kirk-Davidoff, 2006).

Published by Copernicus Publications on behalf of the European Geosciences Union. 

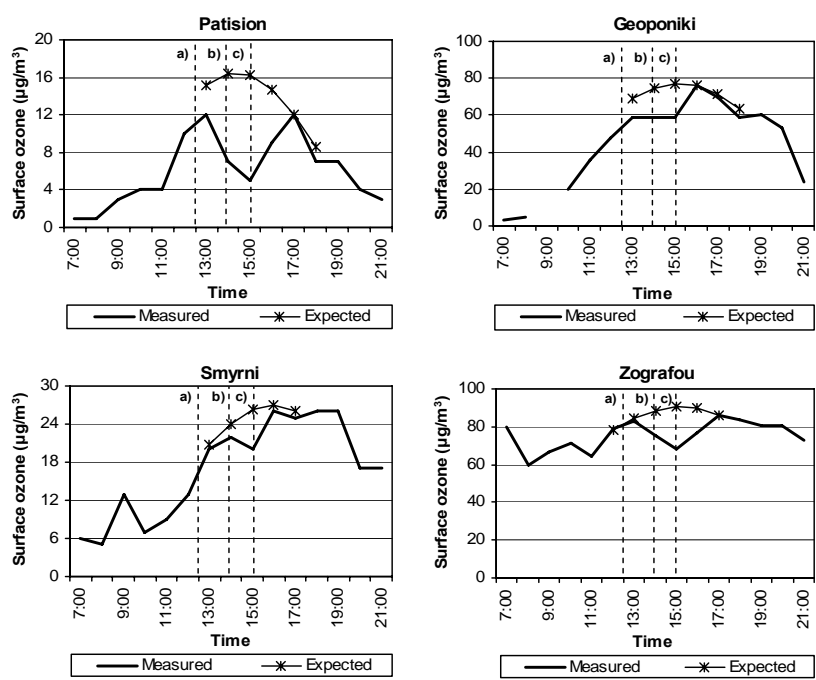

Fig. 1. Surface ozone measurements and the expected surface ozone values as derived from the fitted curve of the measurements before, during and after the eclipse event of 29 March, 2006 at four stations (Patision, Smyrni, Geoponiki and Zografou) in the Athens basin, (a) beginning of the solar eclipse, (b) solar eclipse maximum, (c) end of the solar eclipse.

Although the most important chemical mechanisms involved in photochemical pollution have been already identified and studied, further investigation is necessary because this atmospheric phenomenon is a very complex process involving meteorological, topographic, emission and chemical parameters (Varotsos, 1989, 1994, 2005b; Varotsos et al., 2004).

In this work we examine the behavior of the surface ozone concentration as well as the variations in various meteorological parameters (temperature, relative humidity and wind speed and direction) during the solar eclipse that took place on 29 March 2006 over Athens, Greece $\left(38^{\circ} \mathrm{N}, 23^{\circ} \mathrm{E}\right)$. The results obtained are compared with those that revealed from the observational analysis of the solar eclipse that took place on 11 August, 1999 at Athens.

\section{Data}

We have used the measurements of SOZ concentration along with meteorological measurements, taken at four monitoring stations (Patision, Smyrni, Geoponiki and Zografou). The four sites are located into the greater area of the Athens basin as follows: Patission site in a street of heavy traffic in the centre of the city, Smyrni site at about $5 \mathrm{~km} \mathrm{SE}$ of the centre of the city in an area of low traffic, Geoponiki site at about $2 \mathrm{~km} \mathrm{SW}$ from the centre of the city in an area of low traffic and light industrial activities and Zografou site at about $3 \mathrm{~km} \mathrm{NE}$ of the centre of the city in an 20 area of low traffic inside the campus of the Athens University. SOZ measurements were made with conventional analyzers (APOA,
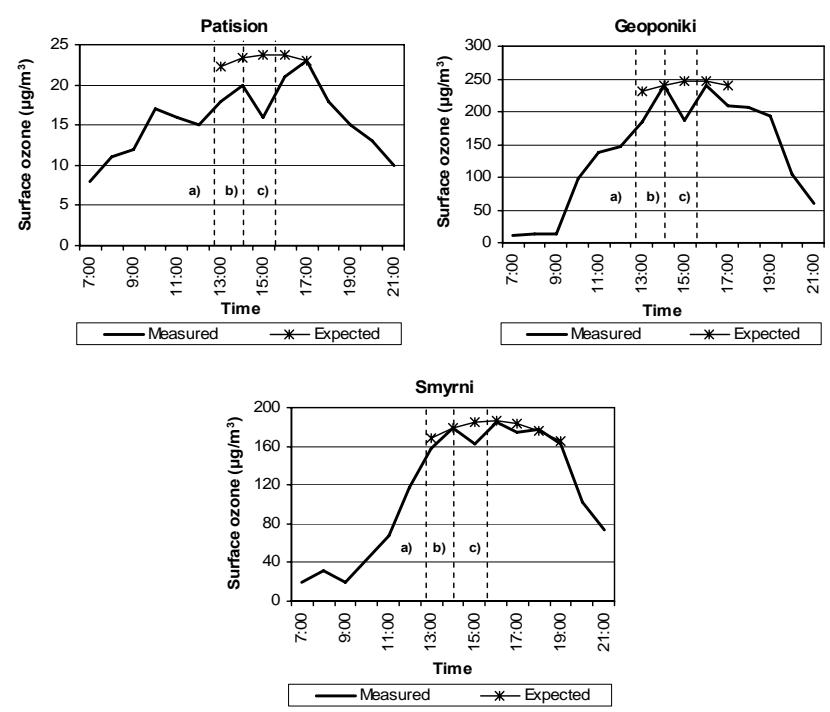

Fig. 2. Surface ozone measurements and the expected surface ozone values as derived from the fitted curve of the measurements before, during and after the solar eclipse of 11 August, 1999 at three stations (Patision, Geoponiki and Smyrni) in the Athens basin, (a) beginning of the solar eclipse, (b) solar eclipse maximum, (c) end of the solar eclipse.

HORIBA Inc., UV absorption) with time resolution $30 \mathrm{~s}$ and accuracy $\pm 2 \mu \mathrm{g} / \mathrm{m}^{3} \mathrm{ppb}$.

At the same locations similar analyzers were also used to obtain observations of the ozone precursors. The selection of the above mentioned monitoring stations was made on the basis that their respective locations give a representative picture of the urban area since they cover four opposite sections. It should be clarified that our data were obtained by the $\mathrm{Na}$ tional Service for Air Pollution Monitoring, which performs 120 measurements per hour reporting hourly means. Therefore, our measurements are the arithmetic mean value of 120 measurements obtained in an hour. The above-mentioned time resolution of our data is adequate because we are going to search for a signal with duration of almost two hours (see figure at http://www.cc.uoa.gr/ nsarlis/gndlayerleveloz/ Figure1.doc in Tzanis et al., 2007).

Solar ultraviolet radiation (SUVR) measurements at 312 and $365 \mathrm{~nm}$ were carried out during the eclipse event by using a VLX-3W (Vilber-Lourmat, France) radiometer equipped with two sensors (CX-312 and CX-365).

In addition, the MICROTOPS II sun-photometer (Solar Light Co., Inc.) was used for measurements of SUVR-B at $312 \mathrm{~nm}$. This filter instrument is a continuation of a series of hand-held ozonometers with TOPS at the beginning. The new generation of those instruments is MICROTOPS II, that is a 5-channel sun-photometer with centre wavelengths of $300,305,312,940$, and $1020 \mathrm{~nm}$ for measurements of TOZ, total water vapour and aerosol optical thickness measurements (Kondratyev and Varotsos, 2000). 


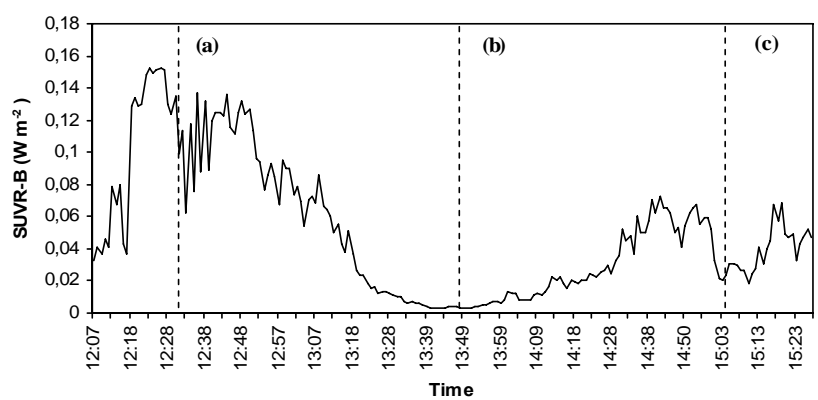

Fig. 3. SUVR-B (312 nm) measurements derived from the MICROTOPS II sun-photometer (Solar Light Co., Inc.), before, during and after the solar eclipse of 29 March, 2006, at Athens, (a) beginning of the solar eclipse, (b) solar eclipse maximum, (c) end of the solar eclipse.

With this instrument TOZ is derived from measurements for three wavelengths in the UV region, given the site's latitude and longitude, universal time, altitude and pressure. As in Dobson instrument the measurement at an additional third wavelength enables a correction for particulate scattering and stray light (Varotsos et al., 1995). The total water vapour is determined through the measurements at $940 \mathrm{~nm}$ and $1020 \mathrm{~nm}$. The angle of view of each of optical channels is $2.5^{\circ}$ and the resolution is $0.001 \mu \mathrm{W} \mathrm{cm}^{-2}$. The typical agreement between various MICROTOPS II instruments (accuracy) is within 1-2\%. The repeatability of consecutive ozone measurements is better than $0.5 \%$. A 21 -months intercomparison of the MICROTOPS II filter ozonometer with the Dobson and Brewer spectrometers resulted that Mtops can measure TOZ with an accuracy comparable to the conventional spectrometers (agreement is better than $\pm 1 \%$ ), over a reasonable range of $\mu$. Adverse conditions (clouds, haze, and low sun) result in deviations of more than $\pm 2 \%$ or even $\pm 3 \%$ (Kondratyev et al., 1995; Kondratyev and Varotsos, 2000; Varotsos et al., 2000).

\section{Discussion and results}

The solar eclipse of 29 March, 2006 at Athens, Greece $\left(38^{\circ} \mathrm{N}, 23^{\circ} \mathrm{E}\right)$ started at $12: 31 \mathrm{LT}$, reached the maximum solar coverage (84\%) at 13:48 and ended at 15:04 LT.

Figure 1 presents the SOZ measurements and the expected $\mathrm{SOZ}$ values as derived from the fitted curve of the measurements, before, during and after the solar eclipse of 29 March 2006, at four stations (Patision, Smyrni, Geoponiki and Zografou) in the Athens basin. The expected values were calculated by applying a 6th degree polynomial fit (best fit) to the observed SOZ concentrations when the eclipse event was absent. All percents in Table 1 were calculated by subtracting the observed SOZ concentrations just before, during and just after the eclipse event from the expected ones. According to Fig. 1 and Table 1, the percentage change of SOZ lasts for
Table 1. Calculated percentage change of surface ozone (at four stations, separately) throughout the eclipse event of 29 March 2006 at Athens, Greece.

\begin{tabular}{rrrrr}
\hline Time & Patision & Geoponiki & Smyrni & Zografou \\
\hline 13:00 & -21.0 & -14.4 & -3.5 & -1.4 \\
$14: 00$ & -57.4 & -21.0 & -8.4 & -15.2 \\
15:00 & -69.3 & -23.5 & -23.8 & -24.8 \\
$16: 00$ & -38.8 & 0.0 & -3.9 & -14.1 \\
\hline
\end{tabular}

Table 2. Calculated percentage change of surface ozone (at three stations, separately) throughout the eclipse event of 11 August 1999 at Athens, Greece.

\begin{tabular}{lrrr}
\hline Time & Patision & Geoponiki & Smyrni \\
\hline $13: 00$ & -19.3 & -20.2 & -6.1 \\
$14: 00$ & -14.2 & 0.0 & 0.0 \\
$15: 00$ & -32.7 & -24.4 & -12.7 \\
$16: 00$ & -11.3 & -2.3 & -1.1 \\
\hline
\end{tabular}

almost two hours and is maximized one hour after the solar eclipse maximum at each of the stations. The greater values of SOZ percentage change are observed at the Patision station, an urban station located in the central part of the Athens basin. This is in agreement with SOZ measurements before, during and after the solar eclipse of 11 August 1999 at Patision, Geoponiki and Smyrni stations as it shown in Fig. 2 and Table 2 (Tzanis, 2005). The above mentioned behavior of SOZ during the solar eclipse may be related to photochemical processes due to the fact that the gradual decrease in the solar radiation affects the photochemical reactions within the planetary boundary layer. The decrease in SOZ concentration started after the beginning of the eclipse and maximized after the solar eclipse maximum as a consequence of the further fall in sunlight intensity that decreased the efficiency of the photochemical ozone formation. The solar radiation started to increase after the eclipse totality while the SOZ concentration started to increase about one hour later and returned to its ordinary behavior several minutes after the end of the solar eclipse. The SOZ variations detected at Athens, before, during and after the solar eclipse of 29 March, 2006 demonstrated that the influence of the phenomenon was manifested with a certain delay and lasted almost two hours.

The observed SUVR measurements at 312 and $365 \mathrm{~nm}$ as derived from the MICROTOPS II sun-photometer and the VLX-3W radiometer, before, during and after the solar eclipse of 29 March, 2006 at Athens are shown in Figs. 3 and 4. As can be seen, the percentage decrease of SUVR-B $(312 \mathrm{~nm})$ which was measured by the MICROTOPS II and VLX-3W instruments reached the value of $97 \%$ and $93 \%$ 


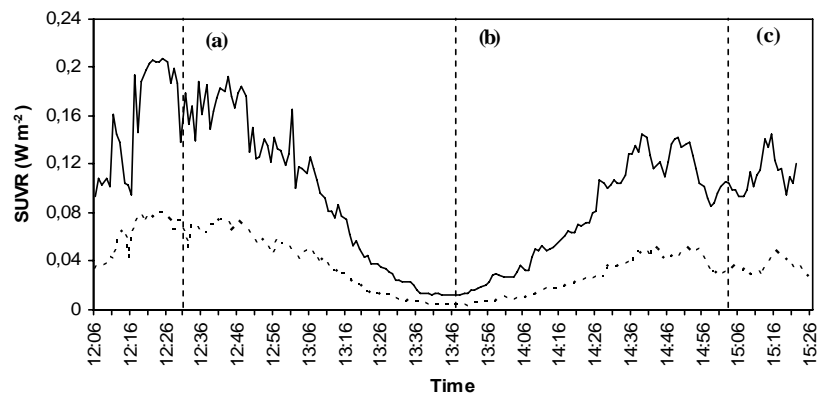

Fig. 4. SUVR (312 and $365 \mathrm{~nm}$ ) measurements derived from the VLX-3W radiometer (Vilber-Lourmat, France), before, during and after the solar eclipse of 29 March, 2006, at Athens, (a) beginning of the solar eclipse, (b) solar eclipse maximum, (c) end of the solar eclipse.

respectively, during the solar eclipse maximum while the change in SUVR at $365 \mathrm{~nm}$ was about $93 \%$. This is in close agreement with the observed reduction in the incoming solar radiation as derived from measurements conducted at Thission station (center of Athens) by Founda et al. (2007).

Figure 5 shows the temporal variation of the relative humidity, temperature and wind velocity during the eclipse at Patision station. Air temperature near the ground decreased from $20.1^{\circ} \mathrm{C}$ to $19.4^{\circ} \mathrm{C}$ during the eclipse event and after that it began to increase abruptly. Relative humidity started to increase at 13:00 $(55 \%)$ as a result of the temperature decrease reaching a maximum (58\%) at the end of the solar eclipse. It is notable that the observed anti-correlation of the temperature and relative humidity curves in Fig. 5 would indicate that the absolute humidity (important parameter to the photochemistry did not change throughout the day.

The fact that the wind speed started to decrease after the solar eclipse maximum, may be attributed to the cooling and the stabilization of the atmospheric boundary layer. The wind speed continued to decrease for two hours after the eclipse event without any significant change in direction. Kolev et al. (2005) observed similar changes in the wind speed in Bulgaria during the solar eclipse of 11 August 1999. The temporal variation of the above mentioned meteorological parameters during the solar eclipse of 29 March, 2006 is in close agreement with observations at three other stations (Thission, Penteli, Markopoulo) in the Athens basin reported by Founda et al. (2007).

\section{Conclusions}

During the solar eclipse of 29 March, 2006 measurements of surface ozone concentration, solar ultraviolet radiation and meteorological parameters (relative humidity, temperature and wind velocity) were performed at four sites (Patision, Smyrni, Geoponiki and Zografou) into the greater area of the Athens basin in Greece.

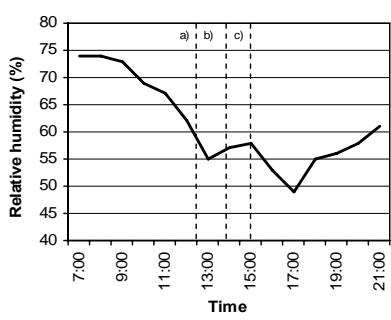

(a)

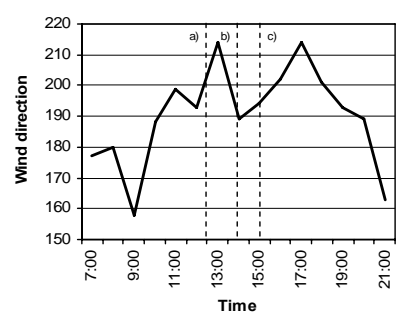

(c)

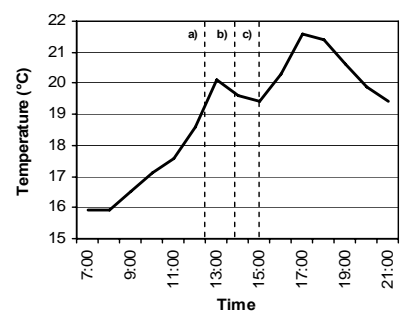

(b)

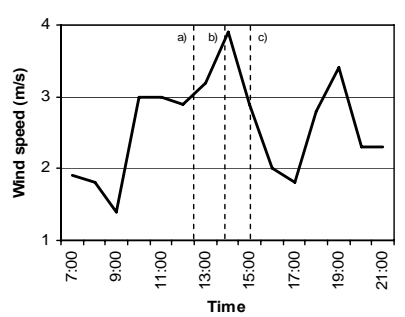

(d)
Fig. 5. Meteorological data obtained at Patision station before, during and after the solar eclipse of 29 March, 2006, (a) beginning of the solar eclipse,(b) solar eclipse maximum, (c) end of the solar eclipse.

As expected, all the parameters mentioned above were affected by the solar eclipse.

The percentage decrease of the SUVR at 312 and $365 \mathrm{~nm}$ reached $97 \%$ and $93 \%$ respectively at the maximum phase of the eclipse.

The SOZ concentration decreased after the eclipse event for almost two hours and the maximum percentage change observed one hour after the maximum of the solar eclipse at all stations. The greater values of SOZ percentage change were observed at Patision station (urban station) located in the center of Athens. The decrease in SOZ concentration was attributed to the dramatic reduction of the solar radiation that affects the photochemical reactions.

The near-ground air temperature dropped about $0.7^{\circ} \mathrm{C}$ during the eclipse event at the center of Athens while the relative humidity increased reaching a maximum at the end of the solar eclipse. The wind speed decreased after the solar eclipse maximum without any significant change in direction.

After the end of the solar eclipse of 29 March, 2006, all the aforementioned parameters exhibited a tendency to regain their ordinary behavior.

Acknowledgements. The authors would like to express their gratitude to the Ministry of Environment, Directorate of Air and Noise Pollution for kindly providing us with data from their stations.

Edited by: P. Monks 


\section{References}

Burnett, C. R. and Burnett, E. B.: Atmospheric hydroxyl response to the partial solar eclipse of May 1984, Geophys. Res. Lett., 12, 263-266, 1985.

Bojkov, R. D.: The ozone variations during the solar eclipse of 20 May 1966, Tellus, 20, 417-421, 1968.

Chimonas, G. and Hines, C. O.: Atmospheric gravity waves induced by a solar eclipse, J. Geophys. Res., 75, p. 875, 1970.

Chimonas, G. and Hines, C. O.: Atmospheric gravity waves induced by a solar eclipse, 2, J. Geophys. Res., 76, 7003-7005, 1971.

Elansky, N. F., Glushchenco, Y. V., Gruzdev, A. N., and Elokhov, A. S.: Measurements of the ozone content in the atmosphere from an aircraft during the solar eclipse on July 31, 1981, Izv. Atmos. Ocean. Phy+., 19, 153-156, 1983.

Fernandez, W., Castro, V., and Hidalgo, H.: Air temperature and wind changes in Costa Rica during the total solar eclipse of July 11, 1991, Earth Moon Planets, 63, 133-147, 1993.

Founda, D., Melas, D., Lykoudis, S., Lisaridis, I., Gerasopoulos, E., Kouvarakis, G., Petrakis, M., and Zerefos, C.: The effect of the total solar eclipse of 29 March 2006 on meteorological variables in Greece, Atmos. Chem. Phys. Discuss., 7, $10631-$ $10667,2007$.

Gerasopoulos, E., Zerefos, C. S., Tsagouri, I., Founda, D.,Amiridis, V., Bais, A. F., Belehaki, A., Christou, N., Economou, G., Kanakidou, M., Karamanos, A., Petrakis, M., and Zanis, P.: The Total Solar Eclipse of March 2006: overview, Atmos. Chem. Phys. Discuss., 7, 17 663-17 704, 2007.

Gogosheva, T. Z., Petkov, B., and Kristev, D.: Measurement of the UV radiation and total ozone during solar eclipse on 11 August 1999, Geomagn. Aeronomy+, 42, 274-278, 2002.

Kolev, N., Tatarov, B., Grigorieva, V., Donev, E., Simeonov, P., Umlensky, V., Kaprielov, B., and Kolev, I.: Aerosol lidar and in situ ozone observations in PBL over Bulgaria during solar eclipse on 11 August 1999, Int. J. Remote Sens., 26, 3567-3584, 2005.

Kondratyev, K. Y., Pokrovsky, O. M., and Varotsos, C. A.: Atmospheric ozone trends and other factors of surface ultraviolet radiation variability, Environ. Conserv., 22(3), 259-261, 1995.

Kondratyev, K. Y. and Varotsos, C.: Atmospheric greenhouse-effect in the context of global climate-change, Nuovo cimento della societa italiana di fisica c-geophysics and space physics, 18(2), 123-151, 1995.

Kondratyev, K. Y. and Varotsos, C.: Atmospheric ozone variability: Implications for climate change, human health and ecosystems, Springer/Praxis, Chichester, U.K., 2000.

Mims, F. M and Mims, E. R.: Fluctuations in column ozone during the total solar eclipse of 11 July 1991, Geophys. Res. Lett., 20, 367-370, 1993.

Reid, S. J., Vaughan, G., Mitchell, N. J., Prichard, I. T., Smit, H. J., Jorgensen, T. S., Varotsos, C., and Debacker, H. : Distribution of ozone laminae during EASOE and the possible influence of inertia-gravity waves, Geophys. Res. Lett., 21(13), 1479-1482, 1994.

Srivastava, G. P., Pakkir, M. P. M., and Balwalli, R. R.: Ozone concentration measurements near the ground at Raichur during the solar eclipse of 1980, P. Indian Acad. Sci. A, 48, 138-142, 1982.

Tzanis, C.: Ground-based observations of ozone at Athens, Greece during the solar eclipse of 1999, Int. J. Remote Sens., 26, 35853596, 2005.
Tzanis, C. et al.: Interactive comment on "Impacts of the solar eclipse of 29 March 2006 on the surface ozone and nitrogen dioxide concentrations at Athens, Greece", Atmos. Chem. Phys. Discuss., 7, S7433-S7436, 2007.

Varotsos, C.: Connections between the 11-year solar-cycle, the QBO and total ozone - comments, J. Atmos. Terr. Phys., 51(5), 367-370, 1989.

Varotsos, C.: Solar ultraviolet-radiation and total ozone, as derived from satellite and ground-based instrumentation, Geophys. Res. Lett., 21(17), 1787-1790, 1994.

Varotsos, C.: The southern hemisphere ozone hole split in 2002, Environ. Sci. Pollut. R., 9(6), 375-376, 2002.

Varotsos, C.: The extraordinary events of the major, sudden stratospheric warming, the diminutive antarctic ozone hole, and its split in 2002, Environ. Sci. Pollut. R., 11(6), 405-411, 2004.

Varotsos, C.: Power-law correlations in column ozone over Antarctica, Int. J. Remote Sens., 26, 3333-3342, 2005a.

Varotsos, C.: Airborne measurements of aerosol, ozone, and solar ultraviolet irradiance in the troposphere, J. Geophys. Res.Atmos., 110(D9), D09202, doi:10.1029/2004JD005397, 2005b.

Varotsos, C., Alexandris, D., Chronopoulos, G., and Tzanis, C.: Aircraft observations of the solar ultraviolet irradiance throughout the troposphere, J. Geophys. Res.-Atmos., 106, $14843-$ $14854,2001$.

Varotsos, C., Cartalis, C., Vlamakis, A., Tzanis, C., and Keramitsoglou, I.: The long-term coupling between column ozone and tropopause properties, J. Climate, 17, 3843-3854, 2004.

Varotsos, C. A., Efstathiou, M. N., and Kondratyev, K. Y.: Longterm variation in surface ozone and its precursors in Athens, Greece - A forecasting tool, Environ. Sci. Pollut. R., 10, 19-23, 2003.

Varotsos, C. and Kirk-Davidoff, D.: Long-memory processes in ozone and temperature variations at the region 60 degrees S-60 degrees N., Atmos. Chem. Phys., 6, 4093-4100, 2006, http://www.atmos-chem-phys.net/6/4093/2006/.

Varotsos, C. A. and Kondratyev, K. Y.: Ozone dynamics over Greece as derived from satellite and in situ measurements, Int. J. Remote Sens., 16, 1777-1798, 1995.

Varotsos, C. A., Kondratyev, K. Y., and Cracknell, A. P.: New evidence for ozone depletion over Athens, Greece, Int. J. Remote Sens., 21(15), 2951-2955, 2000.

Varotsos, C., Kondratyev, K. Y., and Katsikis, S.: On the relationship between total ozone and solar ultraviolet radiation at St. Petersburg, Russia, Geophys. Res. Lett., 22, 3481-3484, 1995.

Varotsos, C., Ondov, J., and Efstathiou, M.: Scaling properties of air pollution in Athens, Greece and Baltimore, Maryland, Atmos. Environ., 39(22), 4041-4047, 2005.

Wuebbles, D. and Chang, J. S.: A theoretical study of stratospheric trace species variations during a solar eclipse, Geophys. Res. Lett., 6, 179-182, 1979.

Zerefos, C. S., Balis, D. S., Meleti, C., Bais, A. F., Tourpali, K., Kourtidis, K., Vanicek, K., Cappellani, F., Kaminski, U., Colombo, T., Stubi, R., Manea, L., Formenti, P., and Andreae, M. O.: Changes in surface solar UV irradiances and total ozone during the solar eclipse of 11 August, 1999, J. Geophys. Res., 105, 26463-26473, 2000.

Zerefos, C. S., Balis, D. S., Zanis, P., Meleti, C., Bais, A. F., Tourpali, K., Melas, D., Ziomas, I., Galani, E., Kourtidis, K., Papayannis, A., and Gogosheva, Z.: Changes in surface UV solar 
irradiance and ozone over the Balkans during the eclipse of $\mathrm{Au}-$ gust 11, 1999, Adv. Space Res., 27, 1955-1963, 2001.

Zerefos, C. S., Gerasopoulos, E., Tsagouri, I., Psiloglou, B., Belehaki, A., Herekakis, T., Bais, A., Kazadzis, S., Eleftheratos, C., Kalivitis, N., and Mihalopoulos, N.: Evidence of gravity waves into the atmosphere during the March 2006 total solar eclipse, Atmos. Chem. Phys. Discuss., 7, 7603-7624, 2007,

http://www.atmos-chem-phys-discuss.net/7/7603/2007/.
Ziomas, I. C., Tzoumaka, P., Balis, D., Melas, D., Zerefos, C. S., and Klemm, O.: Ozone episodes in Athens, Greece. A modelling approach using data from the medcaphot-trace, Atmos. Environ., 32, 2313-2321, 1998. 